\title{
5-Lipoxygenase: underappreciated role of a pro-inflammatory enzyme in tumorigenesis
}

\section{Dieter Steinhilber ${ }^{1}$, Astrid Stefanie Fischer ${ }^{1}$, Julia Metzner ${ }^{1}$, Svenja Dorothea Steinbrink ${ }^{1}$, Jessica Roos ${ }^{2}$, Martin Ruthardt ${ }^{2}$ and Thorsten Jürgen Maier ${ }^{1 *}$}

\author{
Institute of Pharmaceutical Chemistry/ZAFES, Goethe University Frankfurt, Frankfurt, Germany \\ 2 Department of Hematology/ZAFES, Goethe University Frankfurt, Frankfurt, Germany
}

\section{Edited by:}

Angel Lanas, University of Zaragoza

Spain

Reviewed by:

Nicolas Flamand, Université Laval, Canada

Olof Rådmark, Karolinska Institute, Sweden

${ }^{*}$ Correspondence:

Thorsten Jürgen Maier, Institute of Pharmaceutical Chemistry, Goethe University, Max-von-Laue-Street 9 60438 Frankfurt/Main, Germany. e-mail:maier@pharmchem. uni-frankfurt.de
Leukotrienes constitute a group of bioactive lipids generated by the 5-lipoxygenase (5-LO) pathway. An increasing body of evidence supports an acute role for 5-LO products already during the earliest stages of pancreatic, prostate, and colorectal carcinogenesis. Several pieces of experimental data form the basis for this hypothesis and suggest a correlation between 5-LO expression and tumor cell viability. First, several independent studies documented an overexpression of 5-LO in primary tumor cells as well as in established cancer cell lines. Second, addition of 5-LO products to cultured tumor cells also led to increased cell proliferation and activation of anti-apoptotic signaling pathways. 5-LO antisense technology approaches demonstrated impaired tumor cell growth due to reduction of 5-LO expression. Lastly, pharmacological inhibition of 5-LO potently suppressed tumor cell growth by inducing cell cycle arrest and triggering cell death via the intrinsic apoptotic pathway. However, the documented strong cytotoxic off-target effects of 5-LO inhibitors, in combination with the relatively high concentrations of 5-LO products needed to achieve mitogenic effects in cell culture assays, raise concern over the assignment of the cause, and question the relationship between 5-LO products and tumorigenesis.

Keywords: leukotriene, apoptosis, cell proliferation, mitogenic effects, cytotoxicity

\section{INTRODUCTION}

Cancer still ranks the second leading cause of death worldwide despite the emergence of a variety of novel therapeutic options over the past decade. Malignancy of cells reflects an up-regulation of various oncogenic signal cascades that elevate tumor cell proliferation, suppress apoptosis, trigger angiogenesis, and promote metastasis. Lipid mediators, such as leukotrienes (LTs) and prostaglandins constitute a recently discovered class of tumor promoters acting by increasing tumor cell viability and triggering metastasis inducing events. Pharmacological modulation of these biosynthetic pathways is steadily increasing in importance. The present article summarizes several of these experimental findings, which implicate an emerging role of 5-lipoxygenase (5-LO)-derived LTs in carcinogenesis and critically examines the potential shortcomings of previously conducted research. This can provide direction for future investigations on 5-LO in tumorigenesis.

\section{5-LIPOXYGENASE IS A KEY ENZYME IN LEUKOTRIENE BIOSYNTHESIS}

Leukotrienes constitute a group of bioactive lipids that are generated by the 5-LO pathway. 5-LO expression is typically restricted to certain types of leukocytes, such as granulocytes (neutrophils,

Abbreviations: AA, arachidonic acid; $\mathrm{CPLA}_{2 a \mathrm{phh}}$, cytosolic phospholipase $\mathrm{A}_{2 \text { alpha }}$; FLAP, 5-lipoxygenase-activating protein; 5-HETE, 5(S)-hydroxy-8,11,14-cis-6trans-eicosatetraenoic acid; 5-HPETE, 5(S)-hydroperoxy-6-trans-8,11,14-ciseicosatetraenoic acid; 5-LO, 5-lipoxygenase; LT, leukotriene; NDGA, nordihydroguaiaretic acid; PPAR, peroxisome proliferator-activated receptors; RTK, receptor tyrosine kinase; VEGF, vascular endothelial growth factor. eosinophils, and basophils) and monocytes/macrophages, which constitute the major source of LTs due to high 5-LO expression and enzymatic activity. 5-LO expression can also be detected in dendritic cells, mast cells, and B-lymphocytes. LTs primarily mediate inflammatory and allergic reactions (Funk, 2001; Tong et al., 2002; Ohd et al., 2003; Titos et al., 2003; Yoshimura et al., 2003; Zhi et al., 2003; Hayashi et al., 2006) by enhancing chemotaxis of migrating neutrophils and triggering vascular permeability and edema formation in inflamed tissues. Furthermore, LTs are potent bronchoconstrictory agents, crucially involved in asthma pathogenesis, and enhance plaque formation in foam cells of human atherosclerotic tissue. An increasing body of evidence also suggests a potential role of 5-LO products in early stage pancreatic, prostate, and colorectal carcinogenesis (Qiao et al., 1995; Bortuzzo et al., 1996; Avis et al., 2001; Ding et al., 2003; Tong et al., 2005).

5-Lipoxygenase catalyzes the first two steps in LT formation. Biosynthesis begins with dioxygenation of arachidonic acid (AA) released by cytosolic phospholipase $\mathrm{A}_{2 \text { alpha }}\left(\mathrm{CPLA}_{2 \text { alpha }}\right)$ from cellular phospholipids, which results in two chemically unstable intermediates, 5(S)-hydroperoxy-6-trans-8,11,14-cis-eicosatetraenoic acid (5-HPETE) and LTA (Figure 1). A non-heme coordinated iron atom, located in the catalytical site of 5-LO, is involved in both chemical reactions. Depending on the cellular enzymes present, $\mathrm{LTA}_{4}$ can be either converted to $\mathrm{LTB}_{4}$ by $\mathrm{LTA}_{4}$-hydrolase or conjugated with glutathione by $\mathrm{LTC}_{4}$-synthase to generate $\mathrm{LTC}_{4}$. Further processing of $\mathrm{LTC}_{4}$ produces $\mathrm{LTD}_{4}$ and $\mathrm{LTE}_{4}$. 5 -HPETE can be reduced by glutathione peroxidases to form the corresponding 5(S)-hydroxy-6-trans8,11,14-cis-eicosatetraenoic acid (5-HETE; Radmark et al., 2007). 


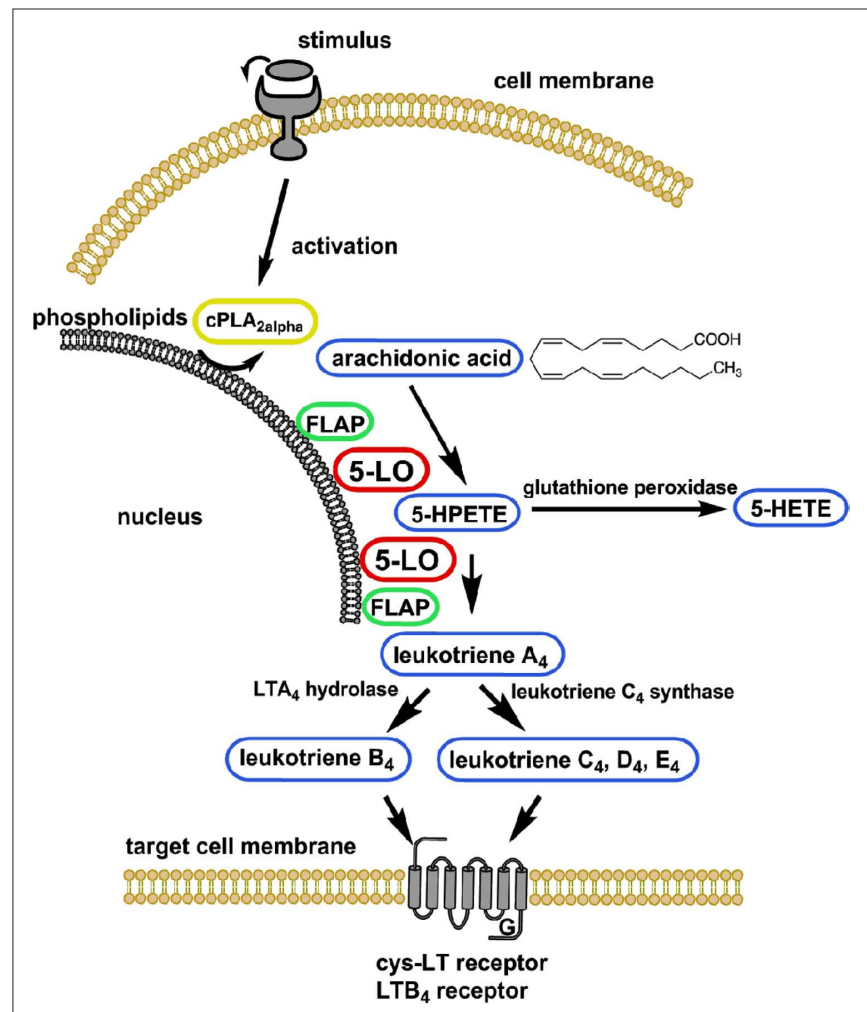

FIGURE 1 | Schematic of leukotriene biosynthesis. For detailed description see Section 5-Lipoxygenase is a Key Enzyme in Leukotriene Biosynthesis. cPLA $_{\text {2alpha' }}$ cytosolic phospholipase $A_{2 a l p h a} ; 5$-HETE, 5(S)-hydroxy-8, 11, 14-cis-6trans-eicosatetraenoic acid; 5-HPETE, 5(S)-hydroperoxy-6-trans-8, 11,14-ciseicosatetraenoic acid; 5-LO, 5-lipoxygenase; FLAP, 5-lipoxygenase-activating protein; LT, leukotriene.

Notably, 5-LO is of importance not only for the biosynthesis of LTs but also of related bioactive eicosanoids, such as 5-oxo-ETE formed by the enzymatic oxidation of 5-HETE (Powell et al., 1992). Furthermore, the lipoxins are formed by the cooperative action of 5- and 15-LO on AA (Serhan et al., 1984) and are involved in programmed resolution of acute inflammation (Levy et al., 2001).

In resting cells, 5-LO resides in either the nucleus or the cytosol, depending on the cell type. Upon activation, 5-LO translocates to the nuclear membrane, where the 5-LO activating protein (FLAP) is thought to facilitate the transfer of phospholipid-derived AA to 5-LO and to enhance the efficiency of conversion of 5-HPETE to $\mathrm{LTA}_{4}$ thereby triggering 5-LO product formation (Abramovitz et al., 1993; Mancini et al., 1993). The LTs produced then exert their biological effects by binding to specific G-protein-coupled transmembrane receptors at the cell surface denoted BLT1/2 for $\mathrm{LTB}_{4}$ and CysLT1/2 activated by the cysteinyl LTs (Funk, 2001).

Several pharmacological strategies exist to suppress 5-LO product formation. Non-redox and redox type inhibitors, including CJ-13,610, Rev-5901, and AA-861 compete with fatty acids for binding to the active site cleft(s). Iron-ligand inhibitors such as zileuton and BWA4C suppress enzyme activity through chelation of the central iron atom and/or by stabilizing the ferrous oxidated state. FLAP inhibitors such as MK-886 act indirectly by interfering with the availability of AA (Ford-Hutchinson et al., 1994).

\section{STUDIES THAT PROVIDE EVIDENCE FOR A ROLE OF 5-LO IN TUMOR CELL PROLIFERATION}

Increasing evidence in literature implicates 5-LO in the growth of several tumor types, including pancreatic, colorectal, prostate, and breast cancer. Numerous studies demonstrated overexpression of 5-LO in tissue samples of primary tumor cells as well as in established cancer cell lines (Chen et al., 2006). Addition of 5-LO products to cultured tumor cells led to increased cell proliferation and activation of anti-apoptotic signaling pathways (Ding et al., 2003; Tong et al., 2005). 5-LO antisense technology approaches impaired tumor cell growth by reducing 5-LO expression (Sveinbjornsson et al., 2008). Finally, pharmacological inhibition of 5-LO has been shown to potently suppress tumor cell growth by inducing cell cycle arrest and triggering cell death via the intrinsic apoptotic pathway (Ghosh and Myers, 1998; Ding et al., 1999). Based on these findings, anti-LT drugs were considered a promising and novel pharmacological strategy for cancer prevention and therapy.

\section{TUMOR-ASSOCIATED OVEREXPRESSION OF 5-L0, LT RECEPTORS AND OTHER ENZYMES INVOLVED IN LT BIOSYNTHESIS}

The first evidence of a potential role for 5-LO in cancer growth was based on expression studies reported by Hong et al. (1999), who reported that 5-LO and FLAP were universally expressed in numerous epithelial cancer cell lines. These findings were in agreement with observations by Hennig et al. (2002), who demonstrated increased expression of 5-LO in a set of human pancreatic cancer cells and a decreased expression in normal pancreatic ductal cells. Subsequently, Gupta et al. (2001) demonstrated 5-LO overexpression in samples taken from prostate carcinoma patients, where the mean level of 5-LO mRNA was sixfold higher in malignant tissues compared to healthy tissues. Overexpression was further documented in malignant pleural mesothelial cells (Romano et al., 2001), in bladder carcinomas (Yoshimura et al., 2003), esophageal tumors (Zhi et al., 2003), and for breast cancer (Jiang et al., 2003).

In support of this hypothesis, an elevated expression of the $\mathrm{LTB}_{4}$ receptor was detected in human pancreatic cancer tissue (Hennig et al., 2002). Assessing colorectal cancer samples from 84 patients, Ohd et al. (2003) were able to show a correlation between expression of CysLT receptors, 5-LO, an increased viability of the tumor cells and declined prognosis for patient survival. Notably, overexpression not only applies to 5-LO but also to other 5-LO binding enzymes involved in LT biosynthesis. Hong et al. (1999) found universal overexpression of FLAP in a series of epithelial cancer cell lines. Overexpression of FLAP associated with higher tumor aggressiveness and a poor prognosis for survival was demonstrated by analyzing breast cancer tissue samples of patients (Jiang et al., 2006). LTA $_{4}$ hydrolase overexpression and activity was found to be an early event in esophageal and oral adenocarcinogenesis (Chen et al., 2004; Sun et al., 2006), whereas a crucial role of $\mathrm{LTC}_{4}$ synthase and $\mathrm{CPLA}_{2 a \mathrm{pha}}$ is evident particularly in pathogenesis of leukemia (Stenke et al., 1998; Sjolinder et al., 2000; Runarsson et al., 2007). Recently, simultaneous overexpression of various enzymes and receptors involved in LT biosynthesis and action, including, 5-LO, FLAP, $\mathrm{LTC}_{4}$ synthase, $\mathrm{LTA}_{4}$ hydrolase, BLT, and CysLT receptors, was detected in the majority of human primary neuroblastoma tumors as well as in respective cell lines. Whereas 5-LO is well-recognized as pro-carcinogenic, the related enzyme 15-LO-2 is down-regulated 
in malignant tissues, considered to function as a tumor suppressor and to inhibit carcinogenesis (Shappell et al., 1999; Hsi et al., 2002). The role of 15-LO-1 is still discussed controversially in the literature (Pidgeon et al., 2007). Depending on the tumor cell type, overexpression of one enzyme of the LT synthesizing machinery in tumor cells does not inevitably account for an overexpression of the other enzymes. Thus, granulocytes from acute myeloid leukemia patients showed suppressed $\mathrm{LTB}_{4}$ formation accompanied by elevated $\mathrm{LTC}_{4}$ hydrolase expression and $\mathrm{LTC}_{4}$ synthesis compared to leukocytes from healthy patients (Stenke et al., 1998).

\section{CYTOTOXIC EFFECTS BY 5-LO INHIBITORS}

Numerous studies have demonstrated cytotoxic and anti-proliferative effects of 5-LO inhibitors in cultured tumor cells as an important basis for the involvement of 5-LO in tumorigenesis. Tsukada et al. were amongst the first to describe the potent anti-proliferative effects of the 5-LO inhibitor AA-861 in a human leukemic cell line. This was accompanied by a sharp reduction in cellular DNA, RNA, and protein synthesis. It was concluded from this result that LTs potentially play an essential role in cancer cell viability (Tsukada et al., 1986). Similar growth-inhibitory effects were observed with the lipoxygenase inhibitor nordihydroguaiaretic acid (NDGA) in stomach cancer cells (Shimakura and Boland, 1992).

These data agree well with studies reporting that the 5-LO inhibitor AA-861 was capable of abolishing the AA stimulated increase of prostate cancer cell growth (Ghosh and Myers, 1997) and that inhibition of 5-LO by MK-886 (FLAP inhibitor) triggers severe apoptosis in human prostate cancer cells (Ghosh and Myers, 1998). Subsequent studies described that AA-861 is capable of suppressing the growth of esophageal cancer cells in vitro (Hoque et al., 2005) and the proliferation of MCF-7 breast cancer cells (Hammamieh et al., 2007). AA-861 also has been shown to have similar effects in colorectal cancer cells (Ihara et al., 2007). Strong cytotoxic effects in various cancer cell lines were also observed with the 5-LO inhibitor and $\mathrm{LTD}_{4}$ receptor antagonist Rev-5901 (Ding et al., 1999; Tong et al., 2002; Titos et al., 2003; Hayashi et al., 2006; Melstrom et al., 2008; Sveinbjornsson et al., 2008). Recent findings with the $\mathrm{LTB}_{4}$ receptor antagonist, LY293111, which demonstrated potent anti-pancreatic cancer effects by inducing tumor cell apoptosis (Ding et al., 2005) and triggering S-phase cell cycle arrest (Tong et al., 2007), further supported the hypothesis that 5-LO and its downstream products, play crucial roles in tumorigenesis. Finally, a chemopreventive activity of Rev-5901 against colorectal adenocarcinoma xenografts was recently demonstrated in an animal tumor model (Melstrom et al., 2008). Taken together, the diverse set of 5-LO inhibitors was shown to suppress the growth of several types of tumor cells by cytotoxic mechanisms, primarily through activation of the intrinsic pathway of apoptosis. However, in addition to the proapoptotic activity of the drugs, it should be noted that additional anti-proliferative effects were observed, such as a decrease in DNA synthesis and induction of cell cycle arrest, which could harbor great significance. A summary of the described drug effects can be found in Table 1 .

\section{MITOGENIC EFFECTS OF 5-LO PRODUCTS}

Several AA metabolites synthesized via the 5-LO pathways have been shown to promote tumor cell viability and to exert protective effects toward the 5-LO inhibitor induced cytotoxicity. The precise molecular mechanisms through which these molecules act on cancer cells remain incompletely understood. Direct proliferative and anti-apoptotic stimuli as well as an enhanced tumor angiogenesis may contribute. 5-HETE and $\mathrm{LTB}_{4}$ increased cell proliferation and viability of pancreatic cancer cells by activating the mitogenic and anti-apoptotic MAPK and Akt kinase signaling pathways (Ding et al., 2003; Tong et al., 2005). A susceptibility toward 5-HETE also was described for several other tumor cell types, including breast cancer (Avis et al., 2001), and cancer of the lung (Avis et al., 1996). The effects of 5-HETE may, at least partially, derive from 5-oxoETE, which is formed by the cellular oxidation of 5-HETE (Powell et al., 1992). 5-oxo-ETE acts by binding to the G-protein-coupled OXE surface receptors (Grant et al., 2009). Some tumor cell types, including colorectal cancer cells, displayed specific mitogenic effects in response to $\mathrm{LTB}_{4}$, but not to other 5-LO products (Qiao et al., 1995; Bortuzzo et al., 1996). A few additional studies report proliferative and anti-apoptotic effects for CysLTs. Accordingly, $\mathrm{LTD}_{4}$

Table 1 | Cytotoxic and anti-proliferative effects by 5-LO inhibitors in cell culture assays.

\begin{tabular}{|c|c|c|c|c|}
\hline Inhibitor & Concentration $(\mu \mathrm{M})$ & Cell type & Effects & Literature \\
\hline AA-861 & 20 & Human leukemia cell lines & Potent anti-proliferative effects & Tsukada et al. (1986) \\
\hline AA-861 & 60 & Human prostate cancer cells & $\begin{array}{l}\text { Inhibition of arachidonic acid } \\
\text { stimulated cell growth }\end{array}$ & Ghosh et al. (1997) \\
\hline MK-886 & 10 & Human prostate cancer cells & $\begin{array}{l}\text { Triggered cell death via activation of } \\
\text { the apoptotic pathway }\end{array}$ & Ghosh et al. (1998) \\
\hline Rev-5901 & 15 & $\begin{array}{l}\text { Human pancreatic cancer cell } \\
\text { lines }\end{array}$ & $\begin{array}{l}\text { Inhibition of cell proliferation, reversal } \\
\text { by } 5 \text {-HETE and } 12 \text {-HETE }\end{array}$ & Ding et al. (1999) \\
\hline LY293111 & 1 & pancreatic cancer cells & $\begin{array}{l}\text { Inhibition of pancreatic cancer growth, } \\
\text { induction of tumor cell apoptosis }\end{array}$ & Ding et al. (2005) \\
\hline AA-861 & 60 & Esophageal cancer cells & $\begin{array}{l}\text { Suppression of cell growth by } \\
\text { induction of apoptosis }\end{array}$ & Hoque et al. (2005) \\
\hline AA-861 & 30 & Human bladder cancer cell lines & Strong growth suppression & Hayashi et al. (2006) \\
\hline MK-591, MK-886 & 20 & MCF-7 breast cancer cell line & Inhibition of cell proliferation & Hammamieh et al. (2007) \\
\hline
\end{tabular}


increased the proliferation and survival of intestinal epithelial cells (Paruchuri et al., 2005) and potentially enhanced tumor growth by up-regulating the transcriptional activity of the oncogenic protein beta-catenin (Mezhybovska et al., 2006). Romano et al. (2001) were able to show that 5(S)-HETE and $\mathrm{LTA}_{4}$ but not $\mathrm{LTB}_{4}$, potently upregulated vascular endothelial growth factor (VEGF) transcription and expression in a human malignant mesothelioma model, which may contribute to the reported pro-angiogenic and anti-apoptotic effects of 5-LO products. Recent findings uncovered a novel function of $\mathrm{LTB}_{4}$ in driving oncogenic ras-induced metastasis by acting on BLT-2 receptors (Kim et al., 2009). Furthermore, LTB $_{4}$-induced breast cancer cell survival was linked to BLT-2 mediated generation of reactive oxygen species. Collectively, the body of research supports a model in which 5 -LO products modulate proliferative and anti-apoptotic events through multiple signaling pathways. Table 2 provides a summary of the described mitogenic effects.

\section{5-LO KNOCK-DOWN STUDIES IN CULTURED CELLS AND IN 5-LO KNOCK-OUT ANIMALS}

Several studies found reduced cell proliferation rates due to downregulation of 5-LO expression by antisense approaches. Using 5-LO antisense oligonucleotides, Romano et al. (2001) were amongst the first to provide direct evidence for 5-LO participation in the growth of malignant pleural mesothelial cells. Moreover, reduced expression of the 5-oxo-ETE receptor by siRNA approaches significantly impaired the viability of prostate cancer cells, suggesting a tumorigenic function of the 5-LO product 5-oxo-ETE (Sundaram and Ghosh, 2006). Finally, silencing of LT receptors was capable of suppressing growth of colorectal cancer cells (Ihara et al., 2007) and neuroblastoma cells (Sveinbjornsson et al., 2008). Comparatively few studies have investigated the role of 5-LO in mouse models. Chen et al. (2009) demonstrated that 5-LO-deficient knock-out (KO) mice show significantly impaired induction of chronic myeloid leukemia through specific suppression of leukemic stem cell proliferation. A summary of experimental findings accounting for a role of 5-LO in tumorigenesis can be found in Figure 2.

\section{STUDIES THAT QUESTION THE ROLE OF 5-LO IN TUMORIGENESIS \\ CYTOTOXIC OFF-TARGET EFFECTS OF 5-LO INHIBITORS}

The increasing number of publications that report a crucial role of 5-LO, and its products in tumorigenesis have been accompanied by additional studies that question the correlation between 5-LO and cancer. There is little disagreement that 5-LO inhibitors exert strong cytotoxic activities against 5-LO overexpressing tumor types and cultured tumor cells, which represents a significant basis for concluding that 5-LO products directly stimulate tumor cell proliferation. However, we recently demonstrated that the common 5-LO inhibitors AA-861, Rev-5901, BWA4C, and CJ-13,610 can reduce the viability of pancreatic cancer cells, cervix carcinoma cells, and leukemic cells independently of suppression of 5-LO product formation (Fischer et al., 2010). The hypothesis of 5-LO-independent cytotoxicity and antiproliferation was substantiated using several experimental approaches. First, the various 5-LO inhibitors were shown to possess highly different abilities to reduce cell viability, to induce cytotoxic effects and to suppress the proliferation of cultured 5-LO-positive Capan-2 pancreas carcinoma cells. While the commonly used inhibitors AA-861, MK-886, and Rev-5901 produced strong cytotoxicity, other, more selective and more potent 5-LO inhibitors, including CJ-13,610, BWA4C, failed in this respect. Notably, zileuton, the only commercialized 5-LO inhibitor, failed to induce an anti-proliferative or cytotoxic response in all types of tumor cells employed. Additionally, the $\mathrm{IC}_{50}$ values of cytotoxicity for AA-861, MK-886, and Rev-5901 exceeded the respective $\mathrm{IC}_{50}$ values for inhibition of 5-LO enzyme activity by more than 20-fold (Rev-5901) and upto 5,000-fold (AA-861). Lastly, wellestablished 5-LO-negative tumor cell lines exhibited a higher susceptibility toward the 5-LO inhibitors than their morphologically related 5-LO-p counterparts. These observations are in line with a report by Datta et al. in which MK-886 induced severe apoptosis independently of FLAP (Datta et al., 1999; Fischer et al., 2010). Sabirsh et al. (2005) recently described 5-LO-independent effects of various LT synthesis inhibitors on $\mathrm{Ca}^{2+}$ signaling in 5-LO-deficient HeLa carcinoma cells. Also the apoptotic effects of licofelone, a dual COX/5-LO inhibitor, were found to occur independently of the ability of the drug to affect the AA cascade (Tavolari et al., 2008).

Recently, the 5-LO inhibitor zileuton was shown to suppress prostaglandin $\mathrm{E}_{2}$ biosynthesis in macrophages with an $\mathrm{IC}_{50}$ value of $1.94 \mu \mathrm{M}$ (Rossi et al., 2010), a value which is close to the $\mathrm{IC}_{50}$ of the drug for suppression of LT production in cell-based assays (Carter et al., 1991). Suppression of the tumor-promoting mediator $\mathrm{PGE}_{2}$ by zileuton was also observed in human whole blood at clinically achievable concentrations and in rats at standard doses. This raises concerns over the relationship between the drugs chemopreventive effects and suppression of 5-LO.

In contrast to this, some non-tumor cell types showed obvious susceptibility toward 5-LO products, such as freshly isolated murine neuronal stem cells, which produced considerable basal amounts of $\operatorname{LTB}_{4}\left(\sim 7 \mathrm{ng}\right.$ per $10^{6}$ cells $)$ and whose growth was suppressed

Table 2 | Mitogenic effects of 5-LO products in cell culture assays.

\begin{tabular}{|c|c|c|c|}
\hline 5-LO product & Cell type & Effect & Literature \\
\hline $\mathrm{LTB}_{4}$ & Colorectal cancer cells & Increase of cell proliferation & Qiao et al. (1995), Bortuzzo et al. (1996) \\
\hline 5-HETE, LTA 4 & $\begin{array}{l}\text { Human malignant pleural } \\
\text { mesothelial cells }\end{array}$ & $\begin{array}{l}\text { Angiogenic and anti-apoptotic effects, in combination with } \\
\text { potent up-regulation of vascular endothelial growth factor }\end{array}$ & Romano et al. (2001) \\
\hline 5-HETE, LTB 4 & Human pancreatic cancer cells & $\begin{array}{l}\text { Stimulation of cell viability and proliferation via } \\
\text { MAPK pathway }\end{array}$ & Ding et al. (2003), Tong et al. (2005) \\
\hline $\mathrm{LTD}_{4}$ & Intestinal epithelial cells & $\begin{array}{l}\text { Increase of cell survival and cell proliferation possibly } \\
\text { mediated via activation of wnt-signaling }\end{array}$ & $\begin{array}{l}\text { Paruchuri et al. (2005), Mezhybovska et } \\
\text { al. (2006) }\end{array}$ \\
\hline
\end{tabular}




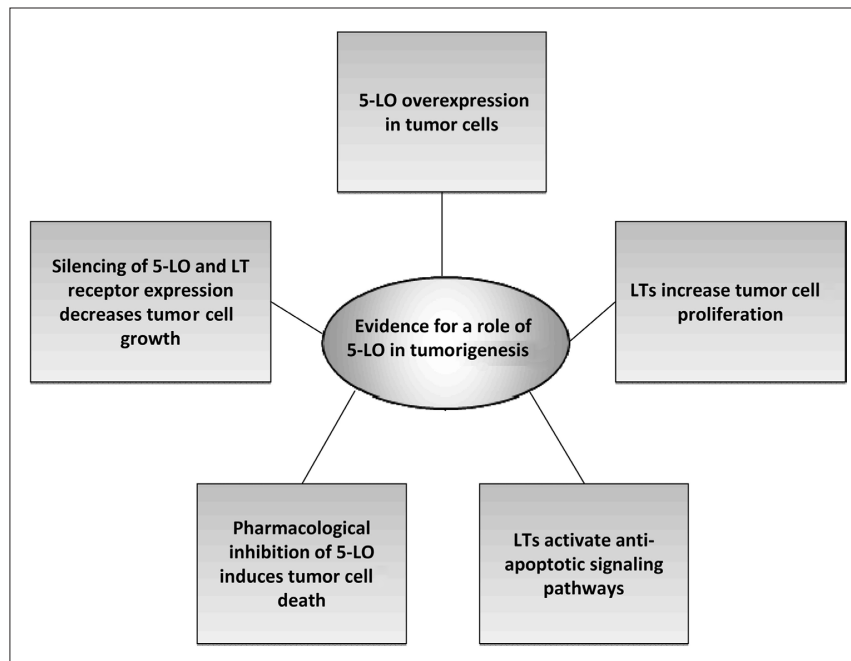

FIGURE 2 | Experimental evidences accounting for a role of 5-LO in tumorigenesis. For detailed description see Section Studies that Provide Evidence for a Role of 5-LO in Tumor Cell Proliferation. 5-LO, 5-lipoxygenase; LT, leukotriene.

by AA-861 at concentrations less than $1 \mu \mathrm{M}$ (Wada et al., 2006). Furthermore, zileuton, the only drug devoid of anti-proliferative and cytotoxic off-target effects (Fischer et al., 2010), was capable of inhibiting the proliferation of RAW 264.7 macrophages below $1 \mu \mathrm{M}$. The macrophages considerably synthesized $\mathrm{LTB}_{4}$ and addition of physiologically relevant concentrations of $\mathrm{LTB}_{4}$ reversed the growth-inhibitory effects of zileuton (Nieves and Moreno, 2006). In sum, in many cases, the cytotoxic and chemopreventive effects 5-LO inhibitors in cell culture assays and in animal tumor models may derive from molecular mechanisms other than suppression of LT biosynthesis and warrant reassessment.

\section{MITOGENIC EFFECTS OF 5-LO PRODUCTS}

Several studies reported accelerated proliferation of tumor cells in the presence of exogenously added 5-LO products and attenuated anti-proliferative effects by 5-LO inhibitors (see Mitogenic Effects of 5-LO Products, page 3, 2nd paragraph). The extreme concentrations frequently required to observe these effects, however, represent one caveat to these experiments; the final concentrations of 5-LO products used often exceeded those present in the medium of untreated cells by up to 10,000-fold (Ghosh and Myers, 1998; Hoque et al., 2005; Sveinbjornsson et al., 2008). Experiments using physiologically relevant concentrations will be one step forward to test the mitogenicity and the pleiotropic effects of 5-LO products. Experiments are also needed to exclude that high concentrations of these 5-LO products induce non-specific anti-apoptotic responses that may counteract diverse stimuli or drugs inducing the intrinsic pathway of apoptosis.

\section{LACKING EVIDENCE FOR A CLINICAL EFFICACY OF 5-LO INHIBITORS IN CANCER THERAPY}

Few clinical trials have assessed the efficacy of anti-LT drugs in clinical cancer therapy. A randomized double-blind phase II study with the $\mathrm{LTB}_{4}$ antagonist LY293111 in patients suffering from advanced adenocarcinoma of the pancreas did not reveal any therapeutic benefit (Saif et al., 2009). This is a surprising result as a significant body of literature has demonstrated a remarkable susceptibility of pancreatic cancer cells toward anti-LT drugs in cell culture studies (see Cytotoxic Effects by 5-LO Inhibitors) and therefore suggests a certain lack of correlation between the effects of 5-LO inhibitors in cell culture assays and in patients. Notably, the mean $C_{\max }$ plasma concentrations of the drug achieved in patients after a dosage of $600 \mathrm{mg}$ BID were found to be $4.4 \mu \mathrm{M}$ (Schwartz et al., 2005) and should lead to almost complete suppression of $\mathrm{LTB}_{4}$ signal transduction (Marder et al., 1995). Consequently, pleiotropic effects of the drug including modulation of PPAR (peroxisome proliferator-activated receptor) signal transduction are currently discussed (Adrian et al., 2008).

\section{CONCLUSION AND FUTURE DIRECTION}

A considerable number of studies has provided evidence for a role of 5-LO in tumorigenesis. The well-recognized overexpression of 5 -LO in various types of malignant cells, the reduction of tumor cell viability by 5 -LO gene silencing approaches, as well as experiments involving 5-LO KO mice, together constitute a substantial rationale for this hypothesis. However, considering that the cytotoxic activity of 5-LO inhibitors is substance-specific and may, in many cases, not derive from inhibition of 5-LO activity, the traditional hypothesis that 5-LO products are the exclusive players in 5-LO-triggered tumorigenesis may warrant reconsideration. Experiments on the role of 5-LO product formation in proliferation of cultured tumor cells using high concentrations $(>1 \mu \mathrm{M})$ of certain 5-LO inhibitors may be misleading and the use of these agents as pharmacological tools should be critically considered. Also, possible indirect tumorigenic effects of 5-LO products (e.g., promotion of angiogenesis) with relevance toward the observed situation in vivo but not for cell culture assays should be taken into account. Notably, non-enzymatic functions, including an interaction with cytoskeleton proteins or with the adaptor protein Grb-2, involved in receptor tyrosine kinase (RTK)-dependent growth factor signaling, have been reported for 5-LO (Lepley and Fitzpatrick, 1994). Because of the crucial role of oncogenic RTK signaling in cancer progression, a disrupted growth factor signaling may contribute to the reduction in tumor cell viability by 5 -LO gene silencing approaches. Thus, experiments that assess Grb-2-dependent growth factor signaling after 5-LO gene silencing may be instructive. Taken together, a broad body of evidence from the literature suggests a crucial, albeit poorly defined, role of 5-LO in tumorigenesis of several cancer types. Elucidation of the molecular mechanisms underlying these effects may include direct proliferative actions of 5-LO products on tumor cells as well as indirect and so far neglected effects of 5-LO and thereby draw novel connections between pathways that are currently regarded as unrelated.

\section{ACKNOWLEDGMENTS}

The authors thank Dr. Wesley McGinn-Straub (California, USA) for the linguistic revision of the manuscript. This work was supported by the "Landes Offensive zur Entwicklung Wissenschaftlich Ökonomischer Exzellenz (LOEWE)/Lipid Signaling Forschungszentrum Frankfurt" (LiFF), and by the German Excellence Cluster "Cardio-Pulmonary System” (ECCPS). 


\section{REFERENCES}

Abramovitz, M., Wong, E., Cox, M. E., Richardson, C. D., Li, C., and Vickers, P. J. (1993). 5-lipoxygenase-activating protein stimulates the utilization of arachidonic acid by 5 -lipoxygenase. Eur. J. Biochem. 215, 105-111.

Adrian, T. E., Hennig, R., Friess, H., and Ding, X. (2008). The Role of PPARgamma receptors and leukotriene $\mathrm{B}(4)$ receptors in mediating the effects of LY293111 in pancreatic cancer. PPAR Res. 2008, 827096.

Avis, I., Hong, S. H., Martinez, A., Moody, T., Choi, Y. H., Trepel, J., Das, R., Jett, M., and Mulshine, J. L. (2001). Fivelipoxygenase inhibitors can mediate apoptosis in human breast cancer cell lines through complex eicosanoid interactions. FASEB J. 15, 2007-2009.

Avis, I. M., Jett, M., Boyle, T., Vos, M. D., Moody, T., Treston, A. M., Martinez, A., and Mulshine, J. L. (1996). Growth control of lung cancer by interruption of 5-lipoxygenase-mediated growth factor signaling. J. Clin. Invest. 97, 806-813.

Bortuzzo, C., Hanif, R., Kashfi, K., Staiano-Coico, L., Shiff, S. J., and Rigas, B. (1996). The effect of leukotrienes B and selected HETEs on the proliferation of colon cancer cells. Biochim. Biophys. Acta 1300, 240-246.

Carter, G. W., Young, P. R., Albert, D. H., Bouska, J., Dyer, R., Bell, R. L., Summers, J. B., and Brooks, D. W. (1991). 5-lipoxygenase inhibitory activity of zileuton. J. Pharmacol. Exp. Ther. 256, 929-937.

Chen, X., Sood, S., Yang, C. S., Li, N., and Sun, Z. (2006). Five-lipoxygenase pathway of arachidonic acid metabolism in carcino-genesis and cancer chemoprevention. Curr. Cancer Drug Targets 6, 613-622.

Chen, X., Wang, S., Wu, N., and Yang, C. S. (2004). Leukotriene A4 hydrolase as a target for cancer prevention and therapy. Curr Cancer Drug Targets 4, 267-283.

Chen, Y., Hu, Y., Zhang, H., Peng, C., and Li, S. (2009). Loss of the Alox 5 gene impairs leukemia stem cells and prevents chronic myeloid leukemia. Nat. Genet. 41, 783-792.

Datta, K., Biswal, S. S., and Kehrer, J. P. (1999). The 5-lipoxygenase-activating protein (FLAP) inhibitor, MK886, induces apoptosis independently of FLAP. Biochem. J. 340( $\mathrm{Pt} 2)$, 371-375

Ding, X. Z., Iversen, P., Cluck, M. W., Knezetic, J.A., and Adrian, T.E. (1999). Lipoxygenase inhibitors abolish proliferation of human pancreatic cancer cells. Biochem. Biophys. Res. Commun. 261, 218-223.
Ding, X. Z., Talamonti, M. S., Bell, R. H. Jr., and Adrian, T. E. (2005). A novel anti-pancreatic cancer agent, LY293111. Anticancer Drugs 16, 467-473.

Ding, X. Z., Tong, W. G., and Adrian, T. E. (2003). Multiple signal pathways are involved in the mitogenic effect of 5(S)-HETE in human pancreatic cancer. Oncology 65, 285-294.

Fischer, A. S., Metzner, J., Steinbrink, S. D., Ulrich, S., Angioni, C., Geisslinger, G., Steinhilber, D., and Maier, T. J. (2010). 5-Lipoxygenase inhibitors induce potent anti-proliferative and cytotoxic effects in human tumour cells independently of suppression of 5-lipoxygenase activity. Br. J. Pharmacol. 161, 936-949.

Ford-Hutchinson, A. W., Gresser, M., and Young, R. N. (1994). 5-Lipoxygenase. Annu. Rev. Biochem. 63, 383-417.

Funk, C. D. (2001). Prostaglandins and leukotrienes: advances in eicosanoid biology. Science 294, 1871-1875.

Ghosh, J., and Myers, C. E. (1997). Arachidonic acid stimulates prostate cancer cell growth: critical role of 5-lipoxygenase. Biochem. Biophys. Res. Commun. 235, 418-423.

Ghosh, J., and Myers, C. E. (1998). Inhibition of arachidonate 5-lipoxygenase triggers massive apoptosis in human prostate cancer cells. Proc. Natl. Acad. Sci. U.S.A. 95 13182-13187.

Grant, G. E., Rokach, J., and Powell, W. S. (2009).5-oxo-ETE and the OXE receptor. Prostaglandins Other Lipid Mediat. 89, 98-104.

Gupta, S., Srivastava, M., Ahmad, N. Sakamoto, K., Bostwick, D. G., and Mukhtar, H. (2001). Lipoxygenase-5 is overexpressed in prostate adenocarcinoma. Cancer 91, 737-743.

Hammamieh, R., Sumaida, D., Zhang, X., Das, R., and Jett, M. (2007). Control of the growth of human breast cancer cells in culture by manipulation of arachidonate metabolism. BMC Cancer 7, 138. doi: 10.1186/1471-2407-7-138

Hayashi, T., Nishiyama, K., and Shirahama, T. (2006). Inhibition of 5-lipoxygenase pathway suppresses the growth of bladder cancer cells. Int. J. Urol. 13, 1086-1091.

Hennig, R., Ding, X. Z., Tong, W. G., Schneider, M. B., Standop, J., Friess, H., Buchler,M.W., Pour,P.M., and Adrian, T. E. (2002). 5-Lipoxygenase and leukotriene $\mathrm{B}(4)$ receptor are expressed in human pancreatic cancers but not in pancreatic ducts in normal tissue. Am. J. Pathol. 161, 421-428.

Hong, S. H., Avis, I., Vos, M. D., Martinez, A., Treston, A. M., and Mulshine, J. L. (1999). Relationship of arachidonic acid metabolizing enzyme expres- sion in epithelial cancer cell lines to the growth effect of selective biochemical inhibitors. Cancer Res. 59, 2223-2228.

Hoque, A., Lippman, S. M., Wu, T. T., Xu, Y., Liang, Z. D., Swisher, S., Zhang, H., Cao, L., Ajani, J. A., and Xu, X C. (2005). Increased 5-lipoxygenase expression and induction of apoptosis by its inhibitors in esophageal cancer: a potential target for prevention. Carcinogenesis 26, 785-791.

Hsi, L. C., Wilson, L. C., and Eling, T. E. (2002). Opposing effects of 15-lipoxygenase- 1 and -2 metabolites on MAPK signaling in prostate. Alteration in peroxisome proliferator-activated receptor gamma. J. Biol. Chem. 277, 40549-40556.

Ihara, A., Wada, K., Yoneda, M., Fujisawa, N., Takahashi, H., and Nakajima, A. (2007). Blockade of leukotriene B4 signaling pathway induces apoptosis and suppresses cell proliferation in colon cancer. J. Pharmacol. Sci. 103, 24-32.

Jiang, W. G., Douglas-Jones, A., and Mansel, R. E. (2003). Levels of expression of lipoxygenases and cyclooxygenase-2 in human breast cancer. Prostaglandins Leukot. Essent. Fatty Acids 69, 275-281.

Jiang, W. G., Douglas-Jones, A. G., and Mansel, R.E. (2006). Aberrant expression of 5-lipoxygenase-activating protein (5-LOXAP) has prognostic and survival significance in patients with breast cancer. Prostaglandins Leukot. Essent. Fatty Acids 74, 125-134.

Kim, E. Y., Seo, J. M., Cho, K. J., and Kim, J.H. (2009). Ras-induced invasion and metastasis are regulated by a leukotriene B4 receptor BLT2-linked pathway. Oncogene 29, 1167-1178.

Lepley, R.A., and Fitzpatrick, F. A. (1994). 5-Lipoxygenase contains a functional Src homology 3-binding motif that interacts with the Src homology 3 domain of Grb2 and cytoskeletal proteins. J. Biol. Chem. 269, 24163-24168.

Levy, B. D., Clish, C. B., Schmidt, B. Gronert, K., and Serhan, C. N. (2001) Lipid mediator class switching during acute inflammation: signals in resolution. Nat. Immunol. 2, 612-619.

Mancini, J. A., Abramovitz, M., Cox, M. E., Wong, E., Charleson, S., Perrier, H., Wang, Z., Prasit, P., and Vickers, P. J. (1993). 5-lipoxygenase-activating protein is an arachidonate binding protein. FEBS Lett. 318, 277-281.

Marder, P., Sawyer, J. S., Froelich, L. L., Mann, L. L., and Spaethe, S. M. (1995). Blockade of human neutrophil activation by 2-[2-propyl-3[3-[2-ethyl-4-(4-fluorophenyl)-5hydroxyphenoxy]propoxy]phenoxy] benzoic acid (LY293111), a nove leukotriene B4 receptor antagonist. Biochem. Pharmacol. 49, 1683-1690. Melstrom, L. G., Bentrem, D. J., Salabat, M. R., Kennedy, T. J., Ding, X.Z., Strouch, M., Rao, S. M., Witt, R. C., Ternent, C. A., Talamonti, M. S., Bell, R. H., and Adrian, T. A. (2008). Overexpression of 5-lipoxygenase in colon polyps and cancer and the effect of 5-LOX inhibitors in vitro and in a murine model. Clin. Cancer Res. 14, 6525-6530.

Mezhybovska, M., Wikstrom, K., Ohd, J. F., and Sjolander, A. (2006). The inflammatory mediator leukotriene D4 induces beta-catenin signaling and its association with antiapoptotic Bcl-2 in intestinal epithelial cells. J. Biol. Chem. 281, 6776-6784.

Nieves, D., and Moreno, J. J. (2006). Role of 5-lipoxygenase pathway in the regulation of RAW 264.7 macrophage proliferation. Biochem. Pharmacol. 72, 1022-1030.

Ohd, J. F., Nielsen, C. K., Campbell, J., Landberg, G., Lofberg, H., and Sjolander, A. (2003). Expression of the leukotriene D4 receptor CysLT1, COX-2, and other cell survival factors in colorectal adenocarcinomas. Gastroenterology 124, 57-70.

Paruchuri, S., Broom, O., Dib, K., and Sjolander, A. (2005). The proinflammatory mediator leukotriene D4 induces phosphatidylinositol 3-kinase and Rac-dependent migration of intestinal epithelial cells. J. Biol. Chem. 280, 13538-13544.

Pidgeon, G.P., Lysaght, J., Krishnamoorthy, S., Reynolds, J.V., O’Byrne, K., Nie, D., and Honn, K. V. (2007). Lipoxygenase metabolism: roles in tumor progression and survival. Cancer Metastasis Rev. 26, 503-524.

Powell, W. S., Gravelle, F., and Gravel, S. (1992). Metabolism of 5(S)-hydroxy6,8,11,14-eicosatetraenoic acid and other 5(S)-hydroxyeicosanoids by a specific dehydrogenase in human polymorphonuclear leukocytes. J. Biol. Chem. 267, 19233-19241.

Qiao, L., Kozoni, V., Tsioulias, G. J., Koutsos, M. I., Hanif, R., Shiff, S. J., and Rigas, B. (1995). Selected eicosanoids increase the proliferation rate of human colon carcinoma cell lines and mouse colonocytes in vivo. Biochim. Biophys. Acta 1258, 215-223.

Radmark, O., Werz, O., Steinhilber, D., and Samuelsson, B. (2007). 5-Lipoxygenase: regulation of expression and enzyme activity. Trends Biochem. Sci. 32, 332-341.

Romano, M., Catalano, A., Nutini, M., D’Urbano, E., Crescenzi, C., Claria, J., Libner, R., Davi, G., and Procopio, A. (2001). 5-lipoxygenase regulates malignant mesothelial cell survival: involvement of vascular endothe- 
lial growth factor. FASEB J. 15, 2326-2336.

Rossi, A., Pergola, C., Koeberle, A., Hoffmann, M., Dehm, F., Bramanti, P., Cuzzocrea, S., Werz, O., and Sautebin, L. (2010). The 5-lipoxygenase inhibitor, zileuton, suppresses prostaglandin biosynthesis by inhibition of arachidonic acid release in macrophages. $B r$. J. Pharmacol. 161, 555-570.

Runarsson, G., Feltenmark, S., Forsell, P. K., Sjoberg, J., Bjorkholm, M., and Claesson, H. E. (2007). The expression of cytosolic phospholipase A2 and biosynthesis of leukotriene B4 in acute myeloid leukemia cells. Eur. J. Haematol. 79, 468-476.

Sabirsh, A., Bristulf, J., Karlsson, U., Owman, C., and Haeggstrom, J. Z. (2005). Non-specific effects of leukotriene synthesis inhibitors on HeLa cell physiology. Prostaglandins Leukot. Essent. Fatty Acids 73, 431-440.

Saif, M. W., Oettle, H., Vervenne, W. L., Thomas, J. P., Spitzer, G., VisserenGrul, C., Enas, N., and Richards, D. A. (2009). Randomized double-blind phase II trial comparing gemcitabine plus LY293111 versus gemcitabine plus placebo in advanced adenocarcinoma of the pancreas. Cancer J. 15, 339-343.

Schwartz, G. K., Weitzman, A., O'Reilly, E., Brail, L., de Alwis, D. P., Cleverly, A., Barile-Thiem, B., Vinciguerra, V., and Budman, D. R. (2005). Phase I and pharmacokinetic study of LY293111, an orally bioavailable LTB4 receptor antagonist, in patients with advanced solid tumors. J. Clin. Oncol. 23, 5365-5373.

Serhan, C. N., Hamberg, M., and Samuelsson, B. (1984). Lipoxins: novel series of biologically active compounds formed from arachidonic acid in human leukocytes. Proc. Natl. Acad. Sci. U.S.A. 81, 5335-5339.

Shappell, S. B., Boeglin, W. E., Olson, S. J., Kasper, S., and Brash, A. R. (1999). 15-lipoxygenase-2 (15-LOX-2) is expressed in benign prostatic epithelium and reduced in prostate adenocarcinoma. Am. J. Pathol. 155, 235-245.

Shimakura, S., and Boland, C. R. (1992). Eicosanoid production by the human gastric cancer cell line AGS and its relation to cell growth. Cancer Res. 52, 1744-1749.

Sjolinder, M., Stenke, L., Nasman-Glaser, B., Widell, S., Doucet, J., Jakobsson, P. J., and Lindgren, J. A. (2000). Aberrant expression of active leukotriene $\mathrm{C}(4)$ synthase in CD16(+) neutrophils from patients with chronic myeloid leukemia. Blood 95, 1456-1464.

Stenke, L., Sjolinder, M., Miale, T. D., and Lindgren, J. A. (1998). Novel enzymatic abnormalities in AML and CML in blast crisis: elevated leucocyte leukotriene $\mathrm{C} 4$ synthase activity paralleled by deficient leukotriene biosynthesis from endogenous substrate. $B r$. J. Haematol. 101, 728-736.

Sun, Z., Sood, S., Li, N., Ramji, D., Yang, P., Newman, R. A., Yang, C. S., and Chen, X. (2006). Involvement of the 5-lipoxygenase/leukotriene A4 hydrolase pathway in 7,12-dimethylbenz[a] anthracene (DMBA)-induced oral carcinogenesis in hamster cheek pouch, and inhibition of carcinogenesis by its inhibitors. Carcinogenesis 27 , 1902-1908.

Sundaram, S., and Ghosh, J. (2006). Expression of 5-oxoETE receptor in prostate cancer cells: critical role in survival. Biochem. Biophys. Res. Commun. 339, 93-98.

Sveinbjornsson, B., Rasmuson, A., Baryawno, N., Wan, M., Pettersen, I., Ponthan, F., Orrego, A., Haeggstrom, J. Z., Johnsen, J. I., and Kogner, P. (2008). Expression of enzymes and receptors of the leukotriene pathway in human neuroblastoma promotes tumor survival and provides a target for therapy. FASEB J. 22, 3525-3536.
Tavolari, S., Bonafe, M., Marini, M., Ferreri, C., Bartolini, G., Brighenti, E., Manara, S., Tomasi, V., Laufer, S., and Guarnieri, T. (2008). Licofelone, a dual COX/5-LOX inhibitor, induces apoptosis in HCA-7 colon cancer cells through the mitochondrial pathway independently from its ability to affect the arachidonic acid cascade. Carcinogenesis 29, 371-380.

Titos, E., Claria, J., Planaguma, A., LopezParra, M., Villamor, N., Parrizas, M., Carrio, A., Miquel, R., Jimenez, W., Arroyo, V., Rivera, F., and Rodes, J. (2003). Inhibition of 5-lipoxygenase induces cell growth arrest and apoptosis in rat Kupffer cells: implications for liver fibrosis. FASEB J. 17, 1745-1747.

Tong, W. G., Ding, X. Z., Talamonti, M. S., Bell, R. H., and Adrian, T. E. (2005). LTB4 stimulates growth of human pancreatic cancer cells via MAPK and PI-3 kinase pathways. Biochem. Biophys. Res. Commun. 335, 949-956.

Tong, W. G., Ding, X. Z., Talamonti, M. S. Bell, R. H., and Adrian, T. E. (2007). Leukotriene B4 receptor antagonist LY293111 induces S-phase cell cycle arrest and apoptosis in human pancreatic cancer cells. Anticancer Drugs 18, 535-541.

Tong, W. G., Ding, X. Z., Witt, R. C., and Adrian, T. E. (2002). Lipoxygenase inhibitors attenuate growth of human pancreatic cancer xenografts and induce apoptosis through the mitochondrial pathway. Mol. Cancer Ther. 1,929-935.

Tsukada, T.,Nakashima, K., and Shirakawa, S. (1986). Arachidonate 5-lipoxygenase inhibitors show potent antiproliferative effects on human leukemia cell lines. Biochem. Biophys. Res. Commun. $140,832-836$.

Wada, K., Arita, M., Nakajima, A. Katayama, K., Kudo, C., Kamisaki, Y., and Serhan, C. N. (2006). Leukotriene B4 and lipoxin A4 are regulatory signals for neural stem cell proliferation and differentiation. Faseb J. 20, 1785-1792.

Yoshimura, R., Matsuyama, M., Tsuchida, K., Kawahito, Y.,Sano, H., and Nakatani, T. (2003). Expression of lipoxygenase in human bladder carcinoma and growth inhibition by its inhibitors. $J$. Urol. 170, 1994-1999.

Zhi, H., Zhang, J., Hu, G., Lu, J., Wang, X., Zhou, C., Wu, M., and Liu, Z. (2003). The deregulation of arachidonic acid metabolism-related genes in human esophageal squamous cell carcinoma. Int. J. Cancer. 106, 327-333.

Conflict of Interest of Statement: The authors declare that the research was conducted in the absence of any commercial or financial relationships that could be construed as a potential conflict of interest.

Received: 02 October 2010; paper pending published: 02 November 2010; accepted: 10 December 2010; published online: 24 December 2010.

Citation: Steinhilber D, Fischer AS, Metzner J, Steinbrink SD, Roos J, Ruthardt $M$ and Maier TJ (2010) 5-Lipoxygenase: underappreciated role of a proinflammatory enzyme in tumorigenesis. Front. Pharmacol. 1:143. doi: 10.3389/ fphar.2010.00143

This article was submitted to Frontiers in Inflammation Pharmacology, a specialty of Frontiers in Pharmacology.

Copyright $\odot 2010$ Steinhilber, Fischer, Metzner, Steinbrink, Roos, Ruthardt and Maier. This is an open-access article subject to an exclusive license agreement between the authors and the Frontiers Research Foundation, which permits unrestricted use, distribution, and reproduction in any medium, provided the original authors and source are credited. 